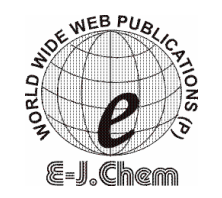

http://www.e-journals.net
ISSN: 0973-4945; CODEN ECJHAO

E-Journal of Chemistry

Vol. 5, No.1, pp. 169-176, January 2008

\title{
Determination and Quantification of Phenytoin in Human Plasma by Liquid Chromatography with Electrospray Ionization Tandem Mass Spectrometry
}

\author{
S.M.N.ROY*, S. M. YETAL, V. V. VAIDYA and S. S. JOSHI, \\ Department of Chemistry, G.N.Khalsa College, Matunga, Mumbai-400 019, India. \\ shikhamonish@yahoo.co.in
}

Received 2 August 2007; Accepted 16 November 2007

\begin{abstract}
A rapid and simple high pressure liquid chromatography method with mass spectrometry detection was developed and validated for the determination of phenytoin in human plasma. Metaxalone was used as internal standard. The sample preparation involves a rapid and simple procedure based on liquid-liquid extraction. Analysis was performed in less than 3.0 minutes in isocratic mode on a reversed phase $\mathrm{C}_{18}$ column $(5 \mu$; $50 \times 4.6 \mathrm{~mm}$ ) using a mobile phase composed of acetonitrile-buffer $2 \mathrm{mM}$ ammonium acetate $(80: 20 \mathrm{v} / \mathrm{v}), \mathrm{pH}$ of buffer adjusted to 3.4 using formic acid, at $0.4 \mathrm{~mL} \mathrm{~min}^{-1}$ flow rate. The calibration curves were linear in the measured range between $101.2 \mathrm{ng} \mathrm{mL}^{-1}$ and $5060.0 \mathrm{ng} \mathrm{mL}^{-1}$. The validated lowest limit of quantification was $101.2 \mathrm{ng} \mathrm{mL}^{-1}$ for phenytoin. The mean relative recovery for drug and Internal standard was found to be $78.33 \%$ and $77.04 \%$, respectively. The described method has the advantage of being rapid and easy and it could be applied in therapeutic monitoring of these drugs in human plasma.
\end{abstract}

Keywords: Phenytoin, Human plasma, LC/MS/MS

\section{Introduction}

Phenytoin has the molecular formula $\mathrm{C}_{15} \mathrm{H}_{12} \mathrm{~N}_{2} \mathrm{O}_{2}$ and the chemical name 5,5-diphenylimidazolidine-2,4-dione with molecular weight of $252.268 \mathrm{~g} \mathrm{~mol}^{-1}$. Phenytoin is an anticonvulsant drug, which is useful in the treatment of epilepsy. The primary site of action appears to be the motor cortex where spread of seizure activity is inhibited. Possibly by promoting sodium efflux from neurons, phenytoin tends to stabilize the threshold against hyper excitability caused by excessive stimulation or environmental changes capable of reducing membrane sodium gradient. This includes the reduction of posttetanic potentiation at synapses. Loss of posttetanic potentiation prevents cortical seizure foci from detonating adjacent cortical areas. Phenytoin reduces the maximal activity of brain stem centers 
responsible for the tonic phase of tonic-clonic (grand mal) seizures ${ }^{1-4}$. Literature reveals that analytical methods have been reported for quantitation of phenytoin from human serum using HPLC with fluorescence, UV, Diode Array Detection. Supercritical fluid chromatography and nephelometric titration have been reported to estimate the drug content of the tablet ${ }^{7-12}$. But the methods were time consuming, complex as more steps were involved in sample preparation and analysis. The present study is aimed for the development of a fast, simple, economic and less sample preparation method for the determination of phenytoin from human plasma using LC-MS/MS ${ }^{14,15}$. Fig. 1 and Fig. 2 represent precursor and product ion mass spectra of phenytoin and metaxalone respectively.

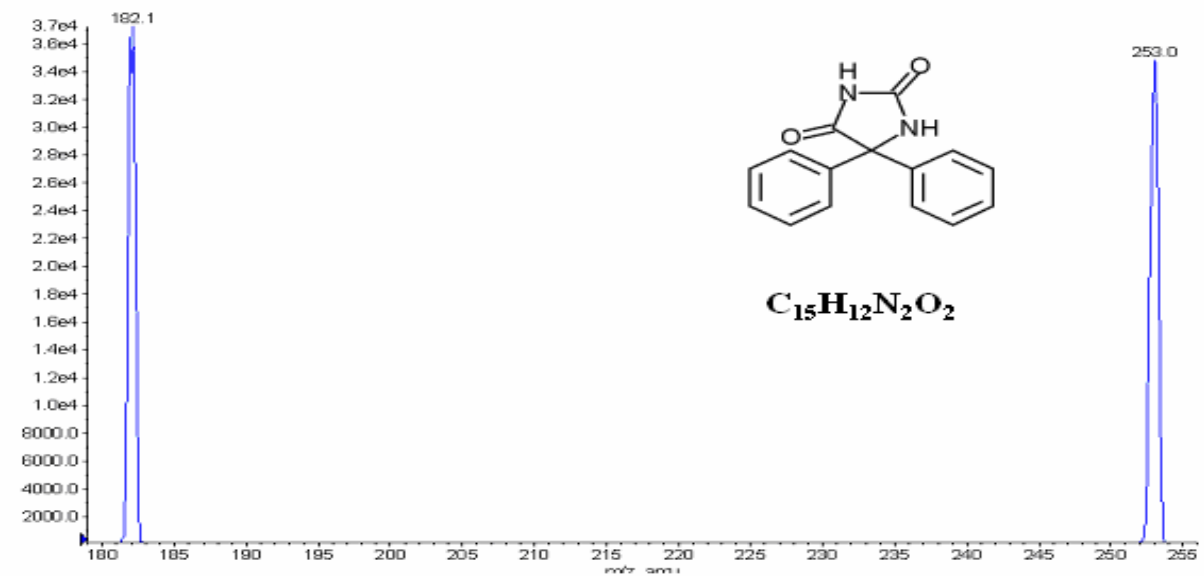

Figure 1. Mass spectra of Phenytoin.

Phenytoin msms scan (Molecular mass: $253.0 \mathrm{~m} / \mathrm{z}$ and Fragment mass : $182.0 \mathrm{~m} / \mathrm{z}$ )

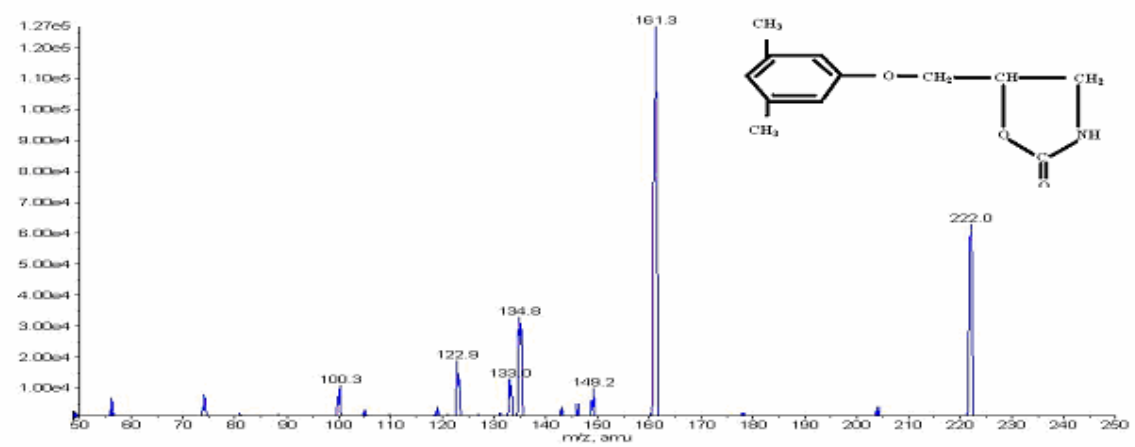

Figure 2. Mass spectra of Metaxalone

Metaxalone msms scan (Molecular mass: $222.1 \mathrm{~m} / \mathrm{z}$ and Fragment mass : $161.1 \mathrm{~m} / \mathrm{z}$ ) 


\section{Experimental}

\section{Chemicals and Reagents}

Working standard of phenytoin sodium was obtained from Alcon Biosciences Pvt.Ltd, India. Working standard of metaxalone was obtained from Prudence Pharma Chem, Ankleshwar, India. Methanol, methyl tertiary butyl ether and acetonitrile of HPLC grade were used of J.T.Baker. Ammonium acetate, $t$-butyl methyl ether and formic acid of HPLC grade obtained from BDH and water of HPLC grade were used.

\section{Instrumentation and chromatographic conditions}

The HPLC system (Shimadzu LC-20AD) consisting of a binary pump, autosampler (SIL-HTc) and detection was performed by an Applied Biosystems. Sciex (API 2000) mass spectrometer using atmospheric turbo ion spray for ion production, which was controlled by Analyst 1.4 software. The column used was Hypersil Hypurity $\mathrm{C}_{18}, 50 \mathrm{x}$ $4.6 \mathrm{~mm}, 5 \mu$. The mobile phase was prepared by mixing $2 \mathrm{mM}$ ammonium acetate buffer and acetonitrile in the ratio of 20:80 $(v / v), \mathrm{pH}$ of buffer adjusted to 3.4 using formic acid. Chromatography was performed at ambient temperature at a flow rate of $0.4 \mathrm{~mL} \mathrm{~min}^{-1}$. The compound was ionized in the positive electro spray ionization (ESI) mode of the mass spectrometer. Analysis was performed in multiple reaction monitoring (MRM) mode; Phenytoin m/z 253.0- 182.0 and Metaxalone 222.1- 161.1

\section{Preparation of the stock solution and validation calibration and quality control samples}

Stock solutions of phenytoin sodium $\left(1012.0 \mu \mathrm{g} \mathrm{mL}^{-1}\right)$ and metaxalone $\left(996.0 \mu \mathrm{g} \mathrm{mL}^{-1}\right)$ was prepared in methanol. Series of working standard solutions with concentrations of 2024.0, 5060.0, 10120.0, 15180.0,20240.0, 50600.0, 80960.0 and $101200.0 \mathrm{ng} \mathrm{mL}^{-1}$ were prepared by dilution of aliquots of stock with methanol and water in the proportion of 60: $40 \mathrm{v} / \mathrm{v}$. Working internal standard solution $\left(10.04 \mu \mathrm{g} \mathrm{mL} \mathrm{m}^{-1}\right)$ was prepared in methanol and water in the proportion of 60: $40 \mathrm{v} / \mathrm{v}$. Low, medium and high quality control solutions (6072.0, 40480.0 and $91080.0 \mathrm{ng} \mathrm{mL}^{-1}$ respectively) were also prepared in methanol and water in the proportion of 60: $40 \mathrm{v} / \mathrm{v}$. Linearity were prepared by spiking blank plasma at concentration of 101.2, 253.0, 506.0, 759.0, 1,012.0, 2,530.0, 4,08.0 and 5,060.0 $\mathrm{ng} \mathrm{mL}^{-1}$ and quality control is 303.6, 2,024.0 and 4,554.0 $\mathrm{ng} \mathrm{mL} \mathrm{m}^{-1}$. Stock solutions were stored at $4-8{ }^{0} \mathrm{C}$ and used within 33 days of preparation.

\section{Sample preparation}

To prepare calibration standards and quality control samples, $25 \mu \mathrm{L}$ of the various diluted working calibration standard and $50 \mu \mathrm{L}$ of internal standard $\left(10.04 \mu \mathrm{g} \mathrm{mL} \mathrm{m}^{-1}\right)$ solution were added to blank plasma to a final volume of $0.50 \mathrm{~mL}$; the contents of the tube vortexes for 30 sec. To each tube $1.5 \mathrm{~mL}$ of methyl $t$-tertiary butyl ether (MTBE) was added and vortexed for 10 minutes followed by centrifugation at $15000 \mathrm{X}$ for 10 minutes. Separated organic layer evaporated at $50{ }^{\circ} \mathrm{C}$ under nitrogen. Dissolved the residue with $500 \mu \mathrm{L}$ of mobile phase and injected into the LC-MS/MS system.

\section{Validation procedures}

\section{Linearity}

Linearity tests were performed in the concentration range of $101.2-5060.0 \mathrm{ng} \mathrm{mL}^{-1}$. Calibration graphs were constructed by plotting peak-area ratios of phenytoin to internal standard against 
nominal concentration (101.2, 253.0, 506.0, 759.0, 1,012.0, 2,530.0, 4,08.0 and 5,060.0 $\left.\mathrm{ng} \mathrm{mL}^{-1}\right)$. The calibration plot was fitted by robust least square fitting using $1 / \mathrm{X}^{2}$ weighing. The linearity of the relationship between peak area ratio and phenytoin concentration is demonstrated by the correlation coefficients obtained for the regression line above $(\mathrm{r}=0.98)$.

\section{Recovery}

Extraction recoveries of phenytoin from spiked samples were determined by comparing the peak areas obtained by extraction of freshly prepared plasma extracts at low, medium and high concentration levels, with those found by direct injection of an aqueous standard solution $^{18}$ at equivalent concentration $(n=6)$.

\section{Precision and accuracy}

The precision of the developed method was determined by analysis of three quality control samples containing 303.6, 2024.0 and $4554.0 \mathrm{ng} \mathrm{mL}^{-1}(\mathrm{n}=6)$. To validate the method for phenytoin, intra day accuracy and precision were evaluated by analysis of three different concentration levels (LQC, MQC, HQC) two set on same day and inter day accuracy and precision were evaluated by analysis at three different concentration levels (LQC, MQC, HQC) on three different days.

\section{Results and Discussion}

\section{Specificity and sensitivity}

The specificity of the analytical method was investigated by analyzing ten different sources of blank plasma samples were extracted and analyzed for the assessment of potential interference with endogenous substances. The apparent response at the retention time of phenytoin and metaxalone were compared to the lower limit of quantification. Fig. 3a and Fig. 3b shows representatitive chromatogram of specificity. The acceptance criteria for phenytoin was mean interference of ten individual source $\leq 20 \%$ of signal at LLOQ and that for metaxalone (internal standard) was mean interference of ten individual source $\leq 5 \%$ of signal at working concentration.

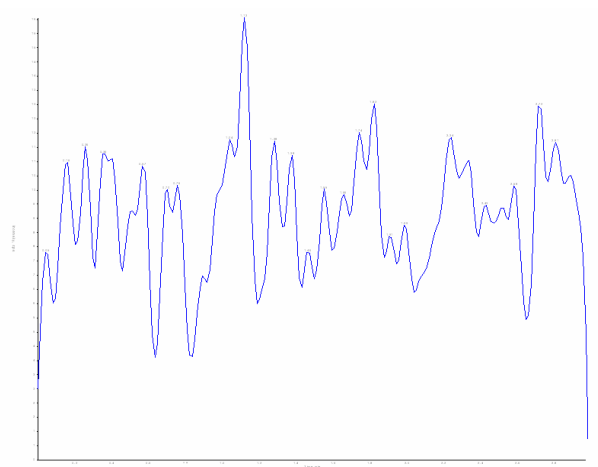

Phenytoin drug

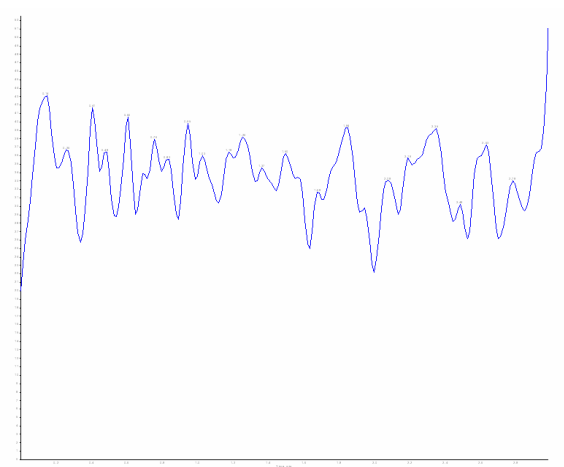

Metaxalone internal standard

Figure 3a. Representative chromatograms of (A) Plasma blank for Phenytoin drug and Metaxalone internal Standard 


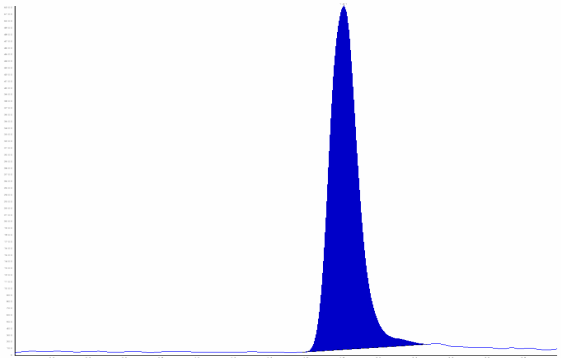

Phenytoin drug (A)

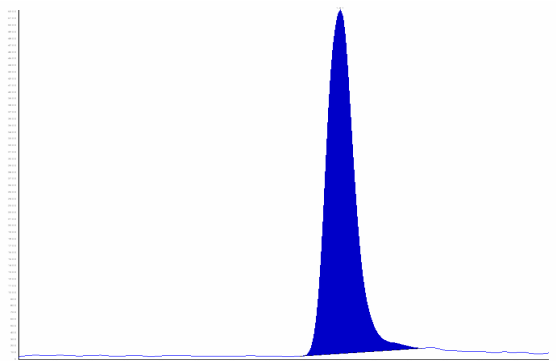

Metaxalone internal standard (B)

Figure 3b. Representative chromatograms of (B) Plasma spiked with Phenytoin drug and Metaxalone internal standard at the lower limit of quatification.

\section{Linearity, precision and accuracy}

Linearity was studied over concentration of $101.2 \mathrm{ng} \mathrm{mL}^{-1}$ to $5060.0 \mathrm{ng} \mathrm{mL}^{-1}$ for phenytoin with correlation coefficients (r) 0.9972. The calculation was done by linear weighed regression $\left(1 / \mathrm{X}^{2}\right)$. The results obtained for linearity, precision and accuracy are listed in Table 1-3. The method shows intra day precision and accuracy for LQC, MQC and HQC levels (303.6, 2024.0 and 4554.0 $\left.\mathrm{ng} \mathrm{mL}^{-1,} \mathrm{n}=6\right)$ are $7.87 \%, 4.37 \%, 5.76 \%$ and $98.25 \%$, $97.40 \%, 91.45 \%$ respectively. The method shows inter day precision and accuracy for LQC, MQC and HQC levels (303.6, 2024.0 and $\left.4554.0 \mathrm{ng} \mathrm{mL}^{-1,} \mathrm{n}=6\right)$ are $5.65 \%, 5.05 \%$, $4.52 \%$ and $94.71 \%, 100.15 \%, 91.44 \%$ respectively.

Table 1. Data of correlation coefficient (r)

\begin{tabular}{cccc}
\hline Calibration curve & \multicolumn{1}{l}{ Slope } & Intercept & Regression \\
\hline 1 & 0.000196 & 0.00373 & 0.9969 \\
2 & 0.000186 & 0.00425 & 0.9976 \\
3 & 0.000237 & 0.00251 & 0.9976 \\
4 & 0.000214 & 0.00212 & 0.9966 \\
Mean & 0.000208 & 0.003153 & 0.9972 \\
\hline
\end{tabular}

Table 2. Data of standard curves

\begin{tabular}{cccc}
\hline Drug & $\begin{array}{c}\text { Nominal concentration } \\
\text { ng mL }^{-1}\end{array}$ & $\begin{array}{c}\text { Mean observed } \\
\text { calculated }\end{array}$ & \\
\hline concentration, ng mL $^{-1}$ & CV, \% \\
Level 2 & 101.2 & 97.971 & 1.781 \\
Level 3 & 253.0 & 266.535 & 1.877 \\
Level 4 & 506.0 & 513.433 & 5.577 \\
Level 5 & 759.0 & 806.993 & 2.425 \\
Level 6 & 1012.0 & 1048.371 & 3.654 \\
Level 7 & 2530.0 & 2362.134 & 2.657 \\
Level 8 & 4048.0 & 3708.534 & 1.165 \\
\hline
\end{tabular}


Table 3. Data of Inter Day Precision and Accuracy

\begin{tabular}{lccccccc}
\hline \multirow{2}{*}{ QC level } & \multicolumn{3}{c}{$\begin{array}{c}\text { Inter day precision and } \\
\text { accuracy }\end{array}$} & \multicolumn{3}{c}{ Intra day precision and accuracy } \\
\cline { 3 - 8 } & $\begin{array}{c}\text { Nominal } \\
\text { concentration } \\
\text { ng mL }^{-1}\end{array}$ & $\begin{array}{c}\text { Mean } \\
\text { observed } \\
\text { Calculated } \\
\text { concentration } \\
\text { ng mL }^{-1}\end{array}$ & $\begin{array}{c}\text { Assay } \\
(\mathrm{n}=6)\end{array}$ & $\begin{array}{c}\text { \% CV } \\
(\mathrm{n}=6)\end{array}$ & $\begin{array}{c}\text { Mean observed } \\
\text { Calculated } \\
\text { concentration } \\
\text { ng mL }\end{array}$ & $\begin{array}{c}\% \\
\text { Assay } \\
(\mathrm{n}=6)\end{array}$ & $\begin{array}{c}\% \mathrm{CV} \\
(\mathrm{n}=6)\end{array}$ \\
\hline LQC & 303.6 & 287.541 & 94.71 & 5.65 & 298.288 & 98.25 & 7.87 \\
MQC & 2024.0 & 2027.014 & 100.15 & 5.05 & 1971.433 & 97.40 & 4.37 \\
HQC & 4554.0 & 4164.36 & 91.44 & 4.52 & 4164.436 & 91.45 & 5.76 \\
\hline
\end{tabular}

Extracted recovery

The extraction recovery of developed method, determined at three LQC, MQC and HQC levels (303.6, 2024.0 and $\left.4554.0 \mathrm{ng} \mathrm{mL}^{-1,} \quad \mathrm{n}=6\right)$ is $79.67 \%, 77.90 \%$ and $77.44 \%$ respectively. Absolute mean \% recovery of the phenytoin and internal standard metaxalone is $78.33 \%$ and $77.04 \%$ respectively. The results obtained for drug and internal standard recovery are listed in Table 4.

Table 4. Extraction recovery for drug and internal standard.

\begin{tabular}{lccclcc}
\hline Drug & $\begin{array}{c}\text { Nominal } \\
\text { concentration } \\
\text { ng mL }^{-1}\end{array}$ & $\begin{array}{c}\text { Mean } \\
\text { Extracted } \\
\text { recovery } \%\end{array}$ & $\begin{array}{c}\% \mathrm{CV} \\
(\mathrm{n}=6)\end{array}$ & $\begin{array}{c}\text { Internal } \\
\text { standard }\end{array}$ & $\begin{array}{c}\text { Mean } \\
\text { Extracted } \\
\text { recovery \% }\end{array}$ & $\begin{array}{c}\% \mathrm{CV} \\
(\mathrm{n}=6)\end{array}$ \\
\hline LQC & 303.6 & 79.67 & 6.59 & LQC & 79.99 & 2.19 \\
MQC & 2024.0 & 77.90 & 3.28 & MQC & 75.90 & 3.64 \\
HQC & 4554.0 & 77.44 & 2.28 & HQC & 75.25 & 3.86 \\
\hline
\end{tabular}

Stability

Stock solutions stored at $4-8{ }^{0} \mathrm{C}$ and used within 33 days. The stock solution stability at room temperature for $24 \mathrm{~h}$ was compared with freshly prepared stock solution of phenytoin. To determine the influence of temperature on the stability of drugs, the plasma quality control samples spiked with drug under different condition. Drug stability shows after three freeze thaw cycle done for LQC and HQC by the present Bias $-4.09 \%$ and $1.90 \%$ respectively. Bench top stability was done for $24 \mathrm{~h}$ at two concentrations LQC and HQC by the present Bias $1.29 \%$ and 5.99\% respectively. Auto sampler stability was done for $24 \mathrm{~h}$ at two concentrations LQC and HQC by the present Bias $-4.81 \%$ and $0.23 \%$. Drug stability in matrix at $-20^{\circ} \mathrm{C}$ for 33 day at two concentrations LQC and HQC s by the present Bias $2.98 \%$ and $14.69 \%$ respectively. The results obtained for stability are listed in Table 5.

Analyte and internal standard responded best to positive ionization using atmospheric turbo ion spray for ion production. In order to get higher response Hypersil, Hypurity (4.6 x $50 \mathrm{~mm}), 5 \mu$ column was used. A number of different columns (Nucleosil, Nova pack, hypersil and symmetry shield) columns were evaluated and Hypurity $(4.6 \times 50 \mathrm{~mm}$ ) was found to give best chromatography with minimal matrix effects. The assay was found to be linear in the concentration range between $101.200 \mathrm{ng}$ $\mathrm{mL}^{-1}$ to $5060.0 \mathrm{ng} \mathrm{mL}^{-1}$ for Phenytoin. Precision and accuracy were satisfactory at the 
three concentration studied. Absolute mean \% recovery of the Phenytoin and Metaxalone is $78.33 \%$ \& $77.04 \%$ respectively. Stability of analyte and internal standard in methanol stock solution was verified ${ }^{5,6,13,16}$ on storage for 33 days at $2-8{ }^{\circ} \mathrm{C}$.

Table 5. Stability Data

\begin{tabular}{cccc}
\hline Stability & $\begin{array}{c}\text { Nominal concentration } \\
\mathrm{ng} \mathrm{mL}^{-1}\end{array}$ & \% Bias & $\begin{array}{c}\% \mathrm{CV} \\
(\mathrm{n}=6)\end{array}$ \\
\hline \multirow{2}{*}{ Bench top } & 303.6 & -1.29 & 10.95 \\
& 4554.0 & -5.99 & 6.28 \\
Freeze- thaw & 303.6 & -4.09 & 6.50 \\
& 4554.0 & -1.90 & 2.70 \\
Auto sampler & 303.6 & -4.81 & 4.91 \\
Drug stability in & 4554.0 & -0.23 & 4.17 \\
matrix & 303.6 & 2.98 & 7.03 \\
\hline
\end{tabular}

\section{Pharmacokinetic application}

Mean Pasma Conœentration (ng/mL) of Phenytoin $300 \mathrm{mg}$ Vs Time in Hrs

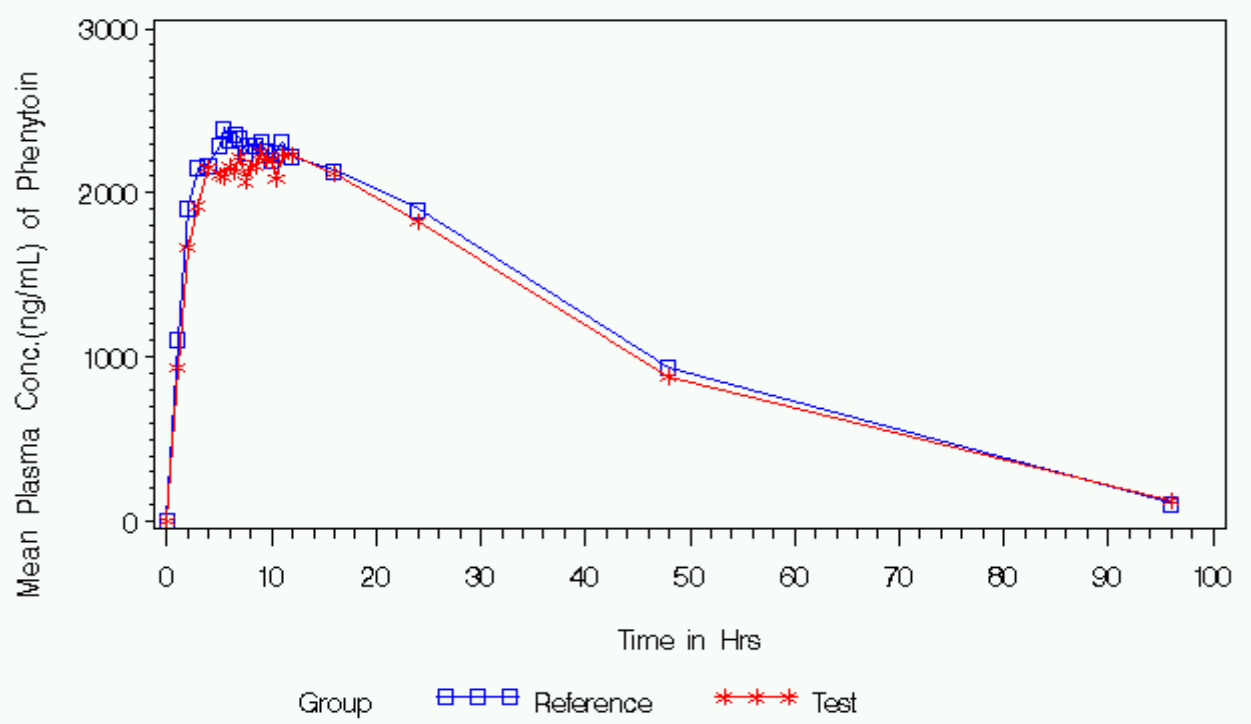

Figure 4. The concentration time profile after a single oral dose bioequivalence study of phenytoin $(300.0 \mathrm{mg})$ capsule.

\section{Conclusion}

Liquid-liquid extraction and LC-MS/MS method with positive ionization polarity provide a fast, sensitive and selective procedure for determination of phenytoin in human plasma. This method is demonstrated of a quantitative assay and should be useful in the routine monitoring of drug concentrations and in pharmacokinetic studies. 


\section{References}

1. Guliz N, Guncu, Feriha Ça layan, Aysun Dinçel, Atilla Bozkurt, Serap Saygı, and Erdem Karabulut, Journal of Periodontology, 2006, 77(22), 2005-2010.

2. Emillio Perucca, Clinical Pharmacokinetics, 2006,45, 351-363.

3. Putman T J and Merritt H H, Science, 1937, 85, 525.

4. Ayala G G and Johnston, Epilepsia, 1977, 18, 299.

5. Patil K M and Bodhankar S L, J Pharm Biomed Anal., 2005, 39, 181-190.

6. Kishore $\mathrm{P}$, Rajnarayana K, Reddy M S, Sagar J V and Krishna D R, Arzneimettelforschung, 2003, 53, 763-8.

7. Santagati N A, Gotti R and Ronsisvalle G, J Sep Sci., 2005, 28, 1157-62.

8. Ritsuko shimoyam, Tadashi ohkubo , Kazunobu sugawara , Tomoka ogasawarb, Takashi ozaki, Akifumi fagiya, and Yoshiharu saito, Journal of Pharmaceutical and Biomedical Analysis, 1998, 17, 863-869,

9. Patil S T, Bhoir I C and Sundaresan M, Analytical Chimica Acta, 1999, 384, 143-150.

10. Natale Alfredo Santagati, Roberto Gotti and Giuseppe Ronsisvalle, Journal of Separation Science, 2005, 28, 1157-1162.

11. Khoschsorur G A, Fruhwirth F and Halwachs-Baumann G, Chromatographia, 2001, 54, 612-1112.

12. Meyler M, Kelly M T and Smyth M R, Chromatographia, 1993, 36, 27-32.

13. Shuuji Hara, Jun Hagiwara, Misa Fukuzawa, Nobufumi ono and Takeshi Kuroda, Analytical Science, 1998, 15, 371-375.

14. Bhatti M M, Hanson G D, Schultz L, Fell Anthony F and Lunte Craig E, Journal of Pharmaceutical and Biomedical Analysis, 1998, 16, 1233-1240.

15. Tao Yi, Xian-Cheng Zhan, Cheng-Rong and Liand Ning He, Chem. Pharm. Bull., 2006, 54, 384-386.

16. Bardin S, Ottinger J C, Breau A P and O'Shea T J, Journal of Pharmaceutical and Biomedical Analysis, 2000, 23, 573-579. 


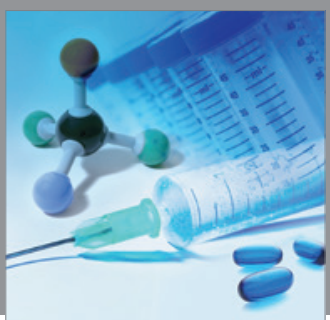

International Journal of

Medicinal Chemistry

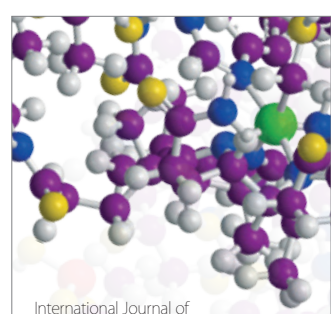

Carbohydrate Chemistry

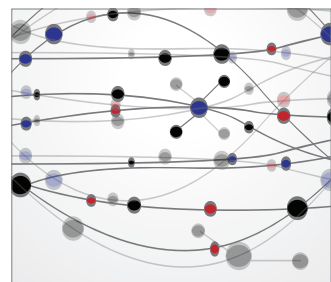

The Scientific World Journal
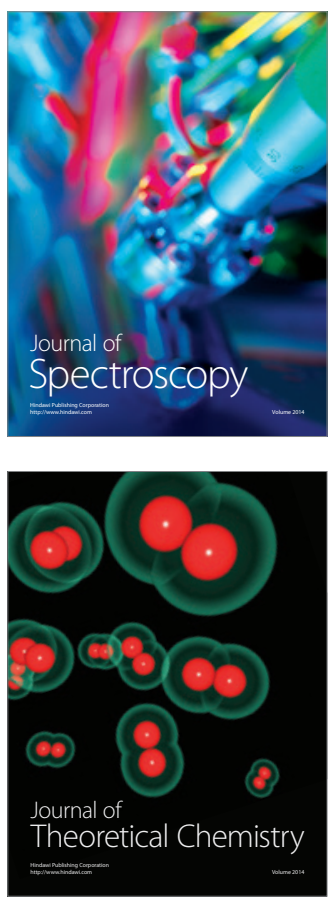
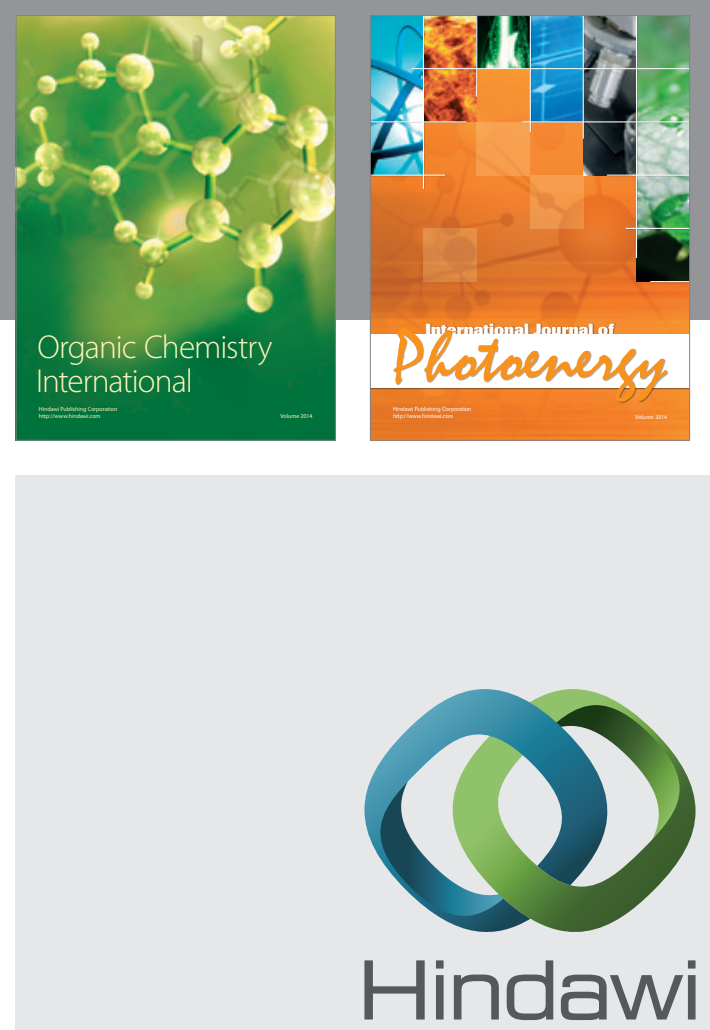

Submit your manuscripts at

http://www.hindawi.com
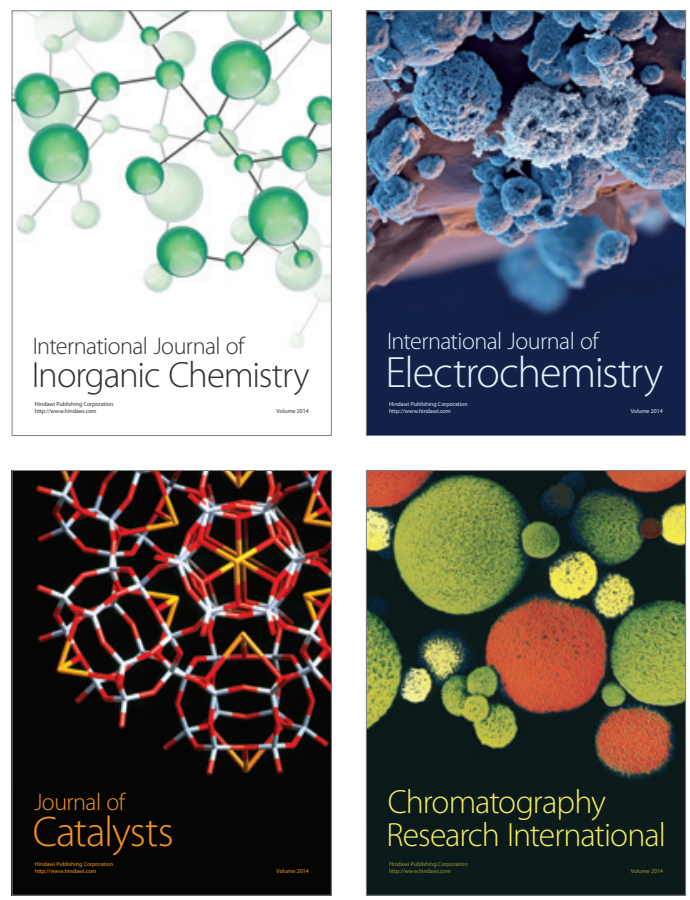
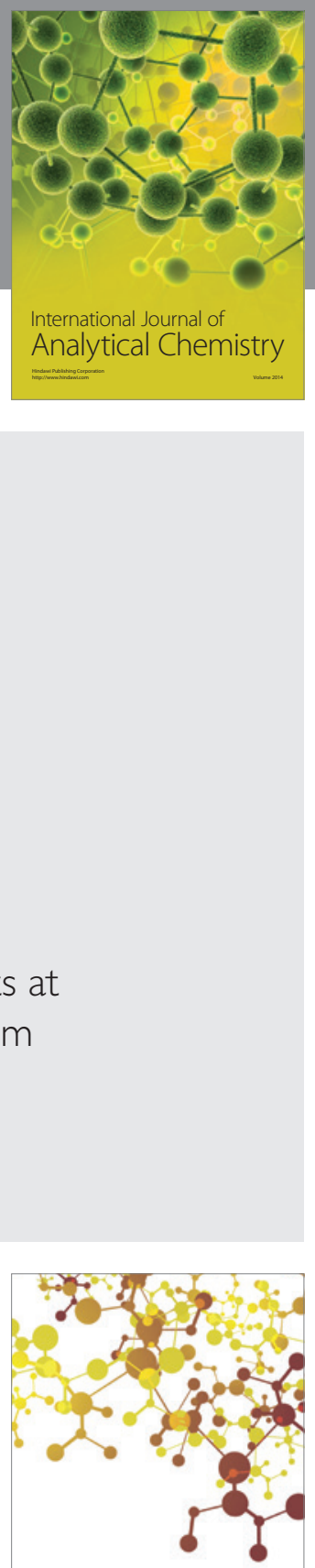

Journal of

Applied Chemistry
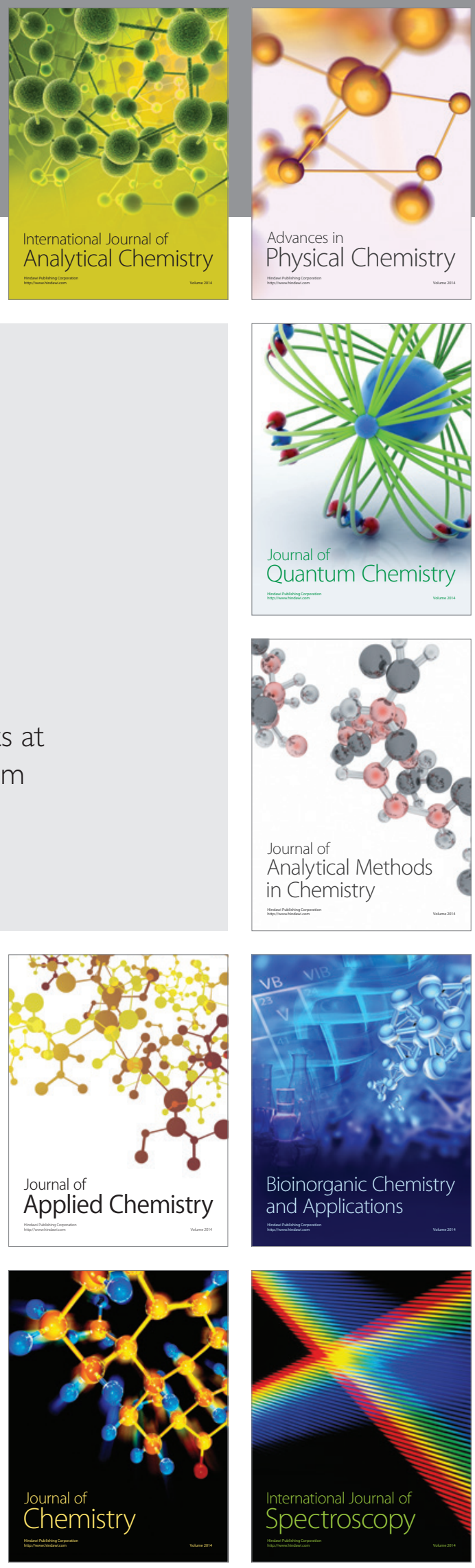